\title{
METHOD FOR PRODUCING FRUIT PASTE USING INNOVATIVE EQUIPMENT
}

\author{
Valeriy Mykhailov \\ Kharkiv State University of Food Technology and Trade \\ Klochkivska str. 333, Kharkiv, Ukraine \\ https://orcid.org/0000-0003-4335-1751 \\ Andrii Zahorulko* \\ Kharkiv State University of Food Technology and Trade \\ Klochkivska str., 333, Kharkiv, Ukraine, zagorulkoan@hduht.edu.ua \\ http://orcid.org/0000-0001-7768-6571 \\ Aleksey Zagorulko \\ Kharkiv State University of Food Technology and Trade \\ Klochkivska str., 333, Kharkiv, Ukraine, zagorulko@hduht.edu.ua \\ (D) http://orcid.org/0000-0003-1186-3832 \\ Bogdan Liashenko \\ Kharkiv State University of Food Technology and Trade \\ Klochkivska str., 333, Kharkiv, Ukraine \\ http://orcid.org/0000-0001-7228-8814 \\ Svetlana Dudnyk \\ Higher Educational Institution of Ukoopspilka "Poltava University of Economics and Trade" \\ Koval str., 3, Poltava, Ukraine \\ https://orcid.org/0000-0001-8228-7276
}

Article history: Received 25 February 2021, Received in revised form 2 April 2021, Accepted 3 April 2021, Available online 3 April 2021.

\begin{abstract}
A method for the production of multicomponent fruit and vegetable paste has been developed. All components were selected considering the content of physiologically functional ingredients. The method is distinguished using the developed innovative equipment: a multifunctional apparatus for the implementation of preliminary heat treatment of raw materials; rotary film evaporator for concentrating puree. The developed devices are distinguished by increased resource efficiency due to heating with a low-temperature film electric heater with a temperature regime in the range of $45-70^{\circ} \mathrm{C}$.

The study of structural and mechanical parameters and organoleptic evaluation of the prototypes allowed to reveal the rational content of raw materials in the developed paste: apples - 30\%; viburnum - 20\%; black chokeberry - $20 \%$; pumpkins $-20 \%$, beets $-10 \%$.
\end{abstract}

\section{Keywords}

fruit and vegetable paste, structural and mechanical characteristics, semi-finished product, concentration

\section{Introduction}

Now in the world there is a deficit in the consumption of plant raw materials, namely fruits and vegetables, in the diets of the population, since their use is usually seasonal and there is no sufficient range of products containing various plant materials. The consumption of such products prevents diseases and aging of the body, has a physiological effect, beneficially affecting one or more target functions of the body, strengthening the health of the population [1].

The solution to this problem is possible by creating food vegetable semi-finished products that combine the beneficial properties of several types of raw materials [2]. A pleasant smell and appearance, an affordable price are the main criteria both when choosing by the consumer and when manufacturing these products. This is especially true of food semi-finished products based on fruit and vegetable raw materials, requiring a gentle mode of heat treatment. The most important technological processes in the production of pastes from fruit and vegetable raw materials are heating, concentration, sterilization and cooling in the flow of a pasty product. 
Heating to a boil and concentrating puree products, in which heat is distributed mainly by thermal conduction, is a complex technical problem.

To improve the conditions for processing plant raw materials into semi-finished products of a high degree of readiness, it is necessary to carry out technical re-equipment of enterprises with effective and reliable equipment that has high productivity, stream organization of processing of raw materials, which will largely eliminate spoilage and loss of physiologically functional ingredients (PFI) due to the short duration and lowtemperature conditions for their processing.

Therefore, the urgent task is to develop new methods to produce multicomponent fruit and vegetable semifinished products of a high degree of readiness with high organoleptic characteristics, nutritional and biological value, low cost and high profitability. The most important natural resource for expanding the range of food products with high nutritional and biological value is fruit and vegetable raw materials [3], the processing of which makes it possible to obtain many different food semi-finished products and finished products.

Multicomponent fruit and vegetable semi-finished products of a pasty state make it possible to provide the population with high-quality products with a high content of biologically active substances throughout the year and create reserves. These semi-finished products, on the one hand, are a source of physiologically functional ingredients, and on the other hand, they can play the role of structure-forming agents, as well as improve the color of food products [4].

Consideration and systematization of the review of literary sources indicates that most of the produced fruit and vegetable pastes are one- or two-component [5]. These semi-finished products have a significant disadvantage, namely, a small amount and uniformity of organic acids, vitamins, and minerals. In addition, their organoleptic characteristics such as color, aroma and taste are insufficiently expressed and aesthetically pleasing. One of the ways to solve this issue is to expand the assortment of pasty semi-finished products by blending several types of plant raw materials, which will provide the product with all groups of physiologically functional ingredients with significant content to ensure their therapeutic and prophylactic properties [6].

The technology for the production of pastes has been tested in the process of concentrating plant raw materials in the form of mashed potatoes to a dry matter content of $24-45 \%$ for $80-400$ minutes in evaporators [7]. It is during the concentration stage that the greatest and significant losses of useful substances of plant raw materials take place. Existing equipment is mostly characterized by high energy and metal consumption due to the use of heat carriers, pipelines and heat generating devices, which reduces their resource efficiency. Such heat supply has the difficulty of stabilizing heat flows, leading to product overheating. There are also difficulties in ensuring uniform distribution of the raw material layer over the entire surface of the device, reducing the product quality. So, now the development of new production methods with the use of efficient equipment and its implementation at food industry enterprises is relevant, will ensure the production of high-quality and enriched pasty semi-finished products through the use of gentle processing modes of raw materials [8].

In the production of fruit and vegetable pastes, it is important to take into account their structural and mechanical parameters in order to carry out calculations of technological equipment, pumps and pipelines, as well as to establish the strength of the resulting structure in multicomponent semi-finished products.

The analysis of the above materials allows to direct research towards improving the production processes of health-improving food products by reducing the concentration temperature within $45-70{ }^{\circ} \mathrm{C}$ [8], this will improve the quality indicators of the obtained semi-finished products and confectionery products based on them.

Thus, the development of new recipes for multicomponent pastes and methods of their production using innovative low-temperature equipment is promising in the creation of preventive semi-finished products and products based on them, which will provide an expansion of the existing range [9].

\section{Methods}

For research, let's use raw fruits and vegetables (Fig. 1), which grows within the Kharkiv region: apple (Antonovka variety), viburnum (Nanum variety), black chokeberry (Chornooka variety), pumpkin (Muscat Pearl variety), beets 
(Bona variety) [10]. The proposed recipe ratio of the compositions of blended fruit and vegetable pastes are given in (Table 1).

Blending of the recipe composition of fruit and vegetable paste was performed taking into account the content of biologically active substances, organoleptic properties and effect of structural and mechanical parameters of each component of raw materials on the consistency of the resulting product. Apples were used as structuring agents with high pectin content; pumpkins and beets served as dietary fiber, in addition, beet has a healing effect on the human body due to unique biochemical composition. Using non-traditional plant raw materials, in particular, guilder rose and black chokeberry, will enrich the pasty semi-finished product with biologically active substances under observing the total acidity at $3.3-3.7 \mathrm{pH}$, which will reduce the pasteurization temperature and extend the shelf life of the semi-finished product.

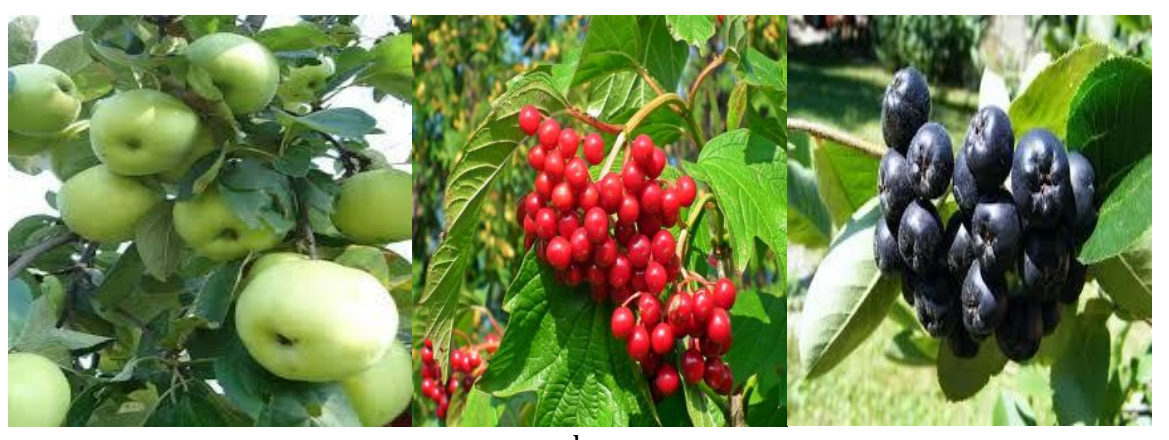

a b c

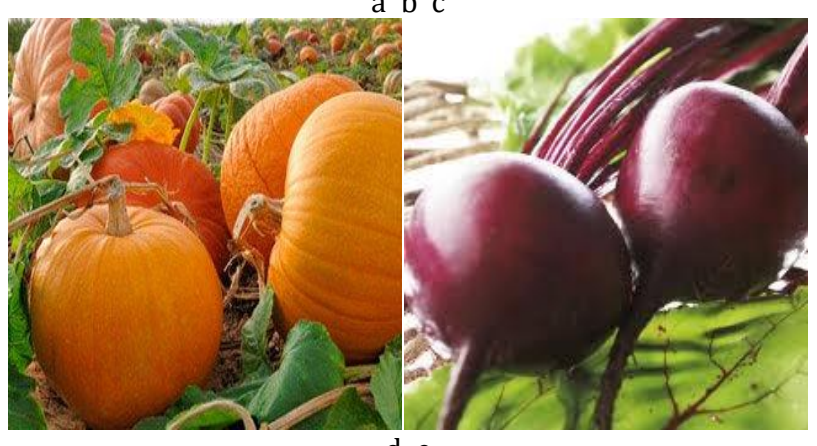

d e

Fig. 1. Appearance of prototypes: a - apple; $b$-viburnum; c-black chokeberry; $d$ - pumpkin; e-beets

Table 1. The ratio of raw materials in blended prototypes

\begin{tabular}{|l|l|l|l|}
\hline \multirow{2}{*}{ Raw material } & \multicolumn{3}{|c|}{ Prototypes } \\
\cline { 2 - 4 } & 1 & 2 & 3 \\
\hline Apple & 40 & 30 & 20 \\
\hline Viburnum & 15 & 20 & 25 \\
\hline Black chokeberry & 15 & 20 & 25 \\
\hline Pumpkin & 25 & 20 & 15 \\
\hline Beet & 5 & 10 & 15 \\
\hline
\end{tabular}

The introduction of various types of raw materials in the paste makes it possible to obtain original formulations with predictable organoleptic and structural-mechanical indicators, as well as an increased content of physiologically functional ingredients (PFI). To establish the rational content of each component of raw materials, prototypes were made with a total weight of $100 \mathrm{~g}$, in three-fold repeated experiments. Changes in the structural and mechanical parameters with an increase in the shear rate in blended samples were compared with a control sample - apple cider paste. Determination of the structural and mechanical characteristics of prototypes of fruit and vegetable pastes was carried out in a rotational viscometer "Reotest-2". The blanching, boiling, blending and mixing processes were carried out in the developed model sample of a multifunctional device, and concentration in an improved rotary film device. The devices differ from analogs by reduced processing time and gentle temperature conditions with snap action control. 


\section{Results and discussion}

The study of the process of creating a recipe for a multicomponent paste using the developed method was carried out on the basis of the Research Center "New biotechnologies and equipment for the production of food products with high health properties" of the Kharkiv State University of Food Technology and Trade (Ukraine).

The composition of the recipe for the developed pasta was created from fruit and vegetable raw materials. The composition was based on apple puree (Antonovka variety), which was mixed with viburnum puree (Nanum variety), black chokeberry (Chornooka variety), pumpkin (Muscat Pearl variety), beet (Bona variety), which have a rich content of functionally physiological ingredients and have therapeutic and prophylactic properties. An apple with a high content of pectin substances, which provides interaction in a multicomponent formulation with other components.

Viburnum berries contain a huge amount of nutrients. Among them are vitamins and minerals, without which the healthy functioning of the body will be simply impossible. Its fruits contain such useful substances: tannins, organic acids, essential oils, vitamin A, ascorbic acid, vitamin P, vitamin E, potassium and magnesium. It is used for the following diseases: diabetes mellitus, cardiovascular diseases, tonsillitis, bronchial asthma, pneumonia, malfunctions of the nervous system, diseases of the digestive system, infectious diseases of the respiratory tract.

Black chokeberry is rich in vitamins $\mathrm{C}$ and $\mathrm{PP}$, carotene, tannins and organic acids. It is often used for hypertension and prevention of atherosclerosis, cardiovascular diseases. It is known that pumpkin is a source of vitamins such as $C, B_{1}, B_{2}, E, P P$, carotenoids, antioxidants - powerful beta-carotene, which is converted into vitamin $A$ in the body and reduces the risk of developing cancer, protects against asthma, supports the heart, inhibits the aging process of the whole organism. Dietary fibers of pumpkin improve the functioning of the gastrointestinal tract, promote bile secretion, and normalize water-salt metabolism.

The chemical composition of beets is represented by pectin, essential amino acids (lysine, valine, arginine, histidine, etc.), vitamins ( $\left.B_{1}, B_{2}, B_{5}, C, B_{3}\right)$, carotenoids, folic acid, organic acids (oxalic, malic), mineral substances (iron, manganese, potassium, calcium, cobalt). It is known that it is beet pectin that is the best entorosorbent, which removes heavy metal salts and toxic substances from the body. The complex of B vitamins contributes to a positive effect on hematopoiesis, and also normalizes the metabolic process.

To substantiate the ratio of puree components of fruit and vegetable raw materials, experiments were carried out with their blending. The content of each individual type of raw material was carried out taking into account the PFI, organoleptic properties and structural and mechanical indicators. The use of non-traditional plant raw materials, namely viburnum and black chokeberry, allows not only to enrich PFI pastes, but also to provide total acidity at the level of 3.2-3.7 $\mathrm{pH}$.

To create a pasty semi-finished product, a method for its production has been developed. The method is distinguished by the use of the developed innovative equipment: a multifunctional apparatus for the implementation of preliminary heat treatment of raw materials; rotary film evaporator for concentrating puree. The developed devices are distinguished by increased resource efficiency due to heating by a flexible film resistive electric heater of the radiant type with a temperature regime of $45-70^{\circ} \mathrm{C}$. Solutions, blanching, cooking and stirring.

In the developed method, the fruits of viburnum and black chokeberry are separately washed, inspected and blanched with water at a temperature of $90{ }^{\circ} \mathrm{C}$ for 2-3 minutes. Then the viburnum and black chokeberry are wiped. The resulting waste peel and bones with the remnants of the pulp are boiled for 5-10 minutes with a ratio of the mass of bones with pulp and peel to the mass of water 1:0.5-1:0.7. The mass thus boiled is rubbed.

For the preparation of apple, beet and pumpkin puree, the existing technology is used for the production of fruit and vegetable purees. The next step is to combine a mass of viburnum and black chokeberry puree, a mashed mass of decoction from their peel and seeds, apple, pumpkin and beet puree and mix until smooth. Blended fruit puree is heated to a temperature of $48-52{ }^{\circ} \mathrm{C}$ and sent for concentration to a rotary film evaporator. Concentration occurs at a temperature of $53-58{ }^{\circ} \mathrm{C}$ to a dry matter content of $44-45 \%$, within $2.2-2.5$ minutes. The resulting pasty semi-finished product is pasteurized and packaged at a temperature of $65-68^{\circ} \mathrm{C}$, sealed and labeled. 
To establish the mechanisms of structure formation and destruction of prototypes, the change in the structural and mechanical characteristics of puree raw materials components and the resulting pastes was investigated. Apple puree and paste were used for control.

Fig. 2 shows the shifting characteristics of the obtained samples of puree from the prescription components of raw materials: apple, viburnum, black chokeberry, pumpkin and beets (Table 1).

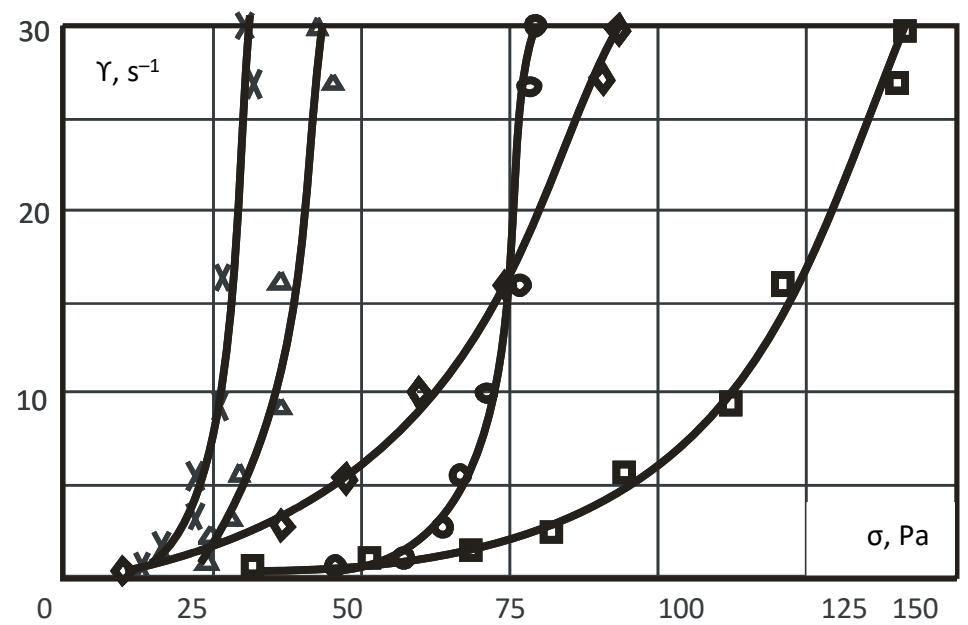

Fig. 2. Shear characteristics of raw material samples in the composition: $০-$ apple; $\Delta$-viburnum: $x-$ black chokeberry; $\diamond-$ pumpkin; - beets $\square$

The curves show that the maximum shear stress for puree of all types of raw materials is greater than zero and is $45 \mathrm{~Pa}$ for apples, $24 \mathrm{~Pa}$ for viburnum, $14 \mathrm{~Pa}$ for black chokeberry, $12 \mathrm{~Pa}$ for pumpkin, and $32 \mathrm{~Pa}$ for beets. All components of the raw material have the ultimate shear stress and their structure is not destroyed immediately after the stress increases, that is, they are characterized as imperfectly plastic solid bodies. This behavior of the ultimate shear stress for puree from fruit and vegetable raw materials is explained by the significant content of dietary fiber. The structural and mechanical characteristics of the developed samples of multicomponent pastes are shown in Fig. 3.

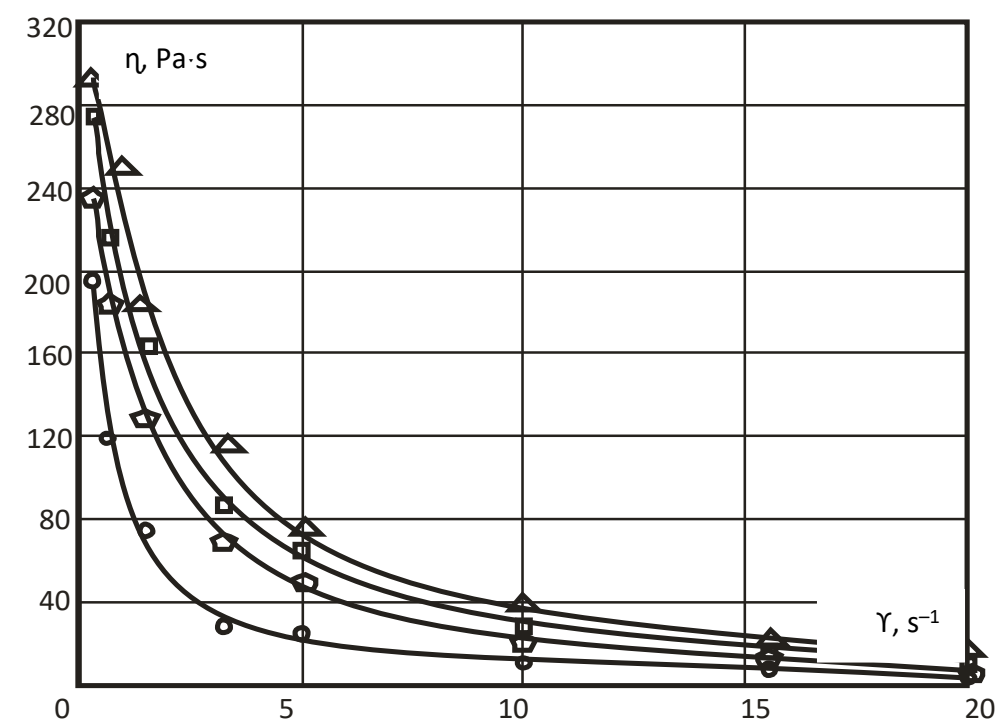

Fig. 3. Rheological curves of multicomponent fruit and vegetable pastes $45 \%$ CP: $\bigcirc$ - control (apple paste) $\Delta-$ sample 1 ; $\square-$ sample $2 ; \square-$ sample 3

The value of the effective viscosity at the moment of shear application for the prototypes is equal to $\eta_{\text {ef }}(\mathrm{Pa} \cdot \mathrm{s})$ : $1-298 ; 2-274 ; 3-237$ and control - 198, respectively. Regarding the obtained indicators, it is possible to see that the introduction of other components into apple raw materials according to the recipe from 60 to $80 \%$ leads to an increase in effective viscosity by 1.2-1.5 times, which indicates the strengthening of the structure of the obtained research threads. 
To determine the quality indicators of the created pasty semi-finished products for their compliance with the established requirements, their organoleptic evaluation was carried out. The results of the organoleptic evaluation of the prototypes are shown in Table 2.

Table 2. Organoleptic evaluation of the developed fruit and vegetable pastes

\begin{tabular}{|c|c|c|c|}
\hline \multirow{2}{*}{ Indicator } & \multicolumn{3}{|c|}{ Sample characteristics } \\
\hline & 1 & 2 & 3 \\
\hline Appearance & \multicolumn{3}{|c|}{ Homogeneous wiped pasty mass } \\
\hline Taste and smell & $\begin{array}{c}\text { Pronounced taste and smell of } \\
\text { apples and pumpkin, beets are } \\
\text { almost not felt }\end{array}$ & $\begin{array}{l}\text { Pleasant harmonious taste } \\
\text { and smell of apples, } \\
\text { viburnum and pumpkin }\end{array}$ & $\begin{array}{c}\text { The smell and taste of } \\
\text { beets are too audible; } \\
\text { pronounced fruits of } \\
\text { viburnum and black } \\
\text { chokeberry }\end{array}$ \\
\hline Color & reddish purple & red violet & Dark purple \\
\hline Consistency & \multicolumn{3}{|c|}{ Homogeneous pasty, formed, does not spread on a flat surface } \\
\hline
\end{tabular}

As a result of the analysis of the data of the structural, mechanical and organoleptic evaluation of the prototypes, it was found that multicomponent fruit and vegetable paste with a content of $30 \%$ apples, viburnum $-20 \%$, black chokeberry $-20 \%$, pumpkin $-20 \%$, beets $-10 \%$ has an advantage (sample 2 ). The introduction of vegetables in large quantities - provides the paste with an unpleasant specific taste and smell; in a small amount of viburnum and black chokeberry - to a decrease in the nutritional value of the semi-finished product.

\section{Impact}

The developed method of production of fruit paste with the use of innovative equipment offers the end profile consumer a multifunctional high-quality a product of organic origin with minimal loss of nutritional value. The introduction of the developed technology with the use of innovative heat and mass transfer equipment in production will help to expand the range of vegetable semi-finished products for further production on their basis of functional and health foods. The introduction of immunomodulatory products into the diet will increase resistance to infectious (including COVID-19) and chronic (cardiovascular, cancer, etc.) diseases.

The expected socio-ecological effect from the implementation of the proposed scientific and technological development will have a positive impact on the social sphere of human society and the environment. The application and use of new organic semi-finished products obtained by the developed technology with innovative equipment in general will form competitiveness and environmental impact in terms of rational processing of organic raw materials. Thus, the method of production of fruit and vegetable paste and appropriate technological equipment has been developed based on the application of innovative aspects of intensification of heat and mass transfer in the processing of fruit and vegetable raw materials on the basis of greater, compared to existing technologies, preservation of nutritional value, improving the efficiency of raw material processing while reducing material and energy costs.

The developed technology and improved equipment offer the end target consumer a multifunctional high-quality product of plant origin with minimal loss of nutritional value, as well as advanced equipment for its processing. The introduction of the developed technology and innovative equipment in the food industry will have a positive impact on the social sphere and the environment, expressed in the wide use of organic food products processed using resource-efficient technologies, which will be more competitive and environmentally friendly.

It should also be noted that the developed equipment, which will be used to carry out the main processes of processing organic fruit and vegetable raw materials, assumes the availability of appropriately qualified personnel, which will ensure the creation of new jobs, the number of which depends on the scale of implementation.

\section{Conclusions}

A method for the production of multicomponent fruit and vegetable paste has been developed. The basis for the paste recipe includes apples, viburnum, pumpkin, beets, and black chokeberry. All components were selected taking into account the content of PFIs in them and their therapeutic and prophylactic properties. The method is distinguished by the use of the developed innovative equipment: a multifunctional apparatus for the 
implementation of preliminary heat treatment of raw materials; rotary film evaporator for concentrating puree. The developed devices are distinguished by increased resource efficiency due to heating with a low-temperature film electric heater with a temperature regime in the range of $45-70{ }^{\circ} \mathrm{C}$. Concentration occurs at a temperature of $53-58{ }^{\circ} \mathrm{C}$ to a dry matter content of $44-45 \%$, for $2.2-2.5$ minutes.

The structural and mechanical parameters of raw material puree samples and fruit and vegetable paste combinations have been investigated. It has been determined that the introduction of 60 to $80 \%$ of other components in apple puree according to the recipe leads to an increase in effective viscosity by 1.2-1.5 times, which indicates the strengthening of the structure of the resulting research threads. The obtained data of structural and mechanical indicators and organoleptic evaluation of pastes made it possible to recommend a rational content of raw material components: apples - 30\%; viburnum - 20\%; black chokeberry - $20 \%$; pumpkins $-20 \%$, beets $-10 \%$.

Further research is planned to be directed to approbation of the developed semi-finished product in confectionery products in order to expand their range and increase nutritional value.

\section{Conflict of interest}

There are no conflicts to declare.

\section{Acknowledgments}

This research has not been supported by any external funding.

\section{References}

[1] A. Yu Prosekov, S.A. Ivanova, Providing food security in the existing tendencies of population growth and political and economic instability in the world, Foods Raw Mater. 4 (2016) 201-211. https://doi.org/10.21179/2308-4057-2016-2-201-211.

[2] T. Bucher, K. van der Horst, M. Siegrist, Fruit for dessert. How people compose healthier meals, Appetite. 60 (2013) 74-80. https://doi.org/10.1016/j.appet.2012.10.003.

[3] A.O. Gayazova, L.S. Prohas'ko, M.A. Popova, S. V. Lukinyh, B.K. Asenova, Ispol'zovanie vtorichnogo i rastitel'nogo syr'ya v produktah funktsional'nogo naznacheniya, Young Sci. 19 (2014) 189-191.

[4] L. Huang, L. Bai, X. Zhang, S. Gong, Re-understanding the antecedents of functional foods purchase: Mediating effect of purchase attitude and moderating effect of food neophobia, Food Qual. Prefer. 73 (2019) 266-275. https://doi.org/10.1016/j.foodqual.2018.11.001.

[5] M. Borchani, M. Masmoudi, A. Ben Amira, F. Abbès, H. Yaich, S. Besbes, C. Blecker, A. Garvin, A. Ibarz, H. Attia, Effect of enzymatic treatment and concentration method on chemical, rheological, microstructure and thermal properties of prickly pear syrup, Lwt. 113 (2019). https://doi.org/10.1016/j.lwt.2019.108314.

[6] L.M. König, B. Renner, Boosting healthy food choices by meal colour variety: Results from two experiments and a just-in-time Ecological Momentary Intervention, BMC Public Health. 19 (2019). https://doi.org/10.1186/s12889-019-7306-z.

[7] A. Zahorulko, A. Zagorulko, M. Yancheva, N. Ponomarenko, H. Tesliuk, E. Silchenko, M. Paska, S. Dudnyk, Increasing the Efficiency of Heat and Mass Exchange in an Improved Rotary Film Evaporator for Concentration of Fruit-Andberry Puree, Eastern-European J. Enterp. Technol. 6 (2020) 32-38. https://doi.org/10.15587/1729-4061.2020.218695.

[8] A. Zahorulko, A. Zagorulko, K. Kasabova, N. Shmatchenko, Improvement of zefir production by addition of the developed blended fruit and vegetable pasteinto its recipe, Eastern-European J. Enterp. Technol. 2 (2020) 39-45. https://doi.org/10.15587/1729-4061.2020.185684.

[9] N.N. Misra, M. Koubaa, S. Roohinejad, P. Juliano, H. Alpas, R.S. Inácio, J.A. Saraiva, F.J. Barba, Landmarks in the historical development of twenty first century food processing technologies, Food Res. Int. 97 (2017) 318-339. https://doi.org/10.1016/j.foodres.2017.05.001.

[10] L.N. Telezhenko, A.T. Bezusov, Biologicheski aktivnye veshchestva fruktov i ovoshchey: sohranenie pri pererabotke, Odessa: Optimym. (2004) 268. 